\title{
Promise and Reality of Practiced Distributed Education (DE) Faculty Perspective
}

\author{
Mary S. McCully \\ National Defense University, Washington, D.C.
}

mccullym@ndu.edu

\section{Abstract}

Student centered. Demonstrable outcomes. Center of gravity shifting from learned to learner. Learn by doing. Collaboration. Critical thinking. Student responsible for learning. Deeper learning. Ongoing feedback. Outcome assessment. Priority on how, not where, a student learns. Life-long learning opportunities. Global access 24/7/365. Effectiveness. Efficiency. Revolution. These are but a few of the touted promises of distributed education (DE) that are supported by new and evolving web based information technologies (IT). Education periodicals bombard their readers with heralds of the IT community's pledge to revolutionize education out of the industrial age of Taylorized mass production of passive students and into the knowledge age of life long active learners. Notable educators predict DE will profoundly affect the traditional classroom, forcing it to follow the DE classroom in becoming more of a student centered active learning environment. (Carnevale, April, 2001; Newman \& Scurry, 2001; Toward a model of distributed learning, 1999) Is there any truth to this hype?

Keywords: Distributed Education (DE), Interactive Distributed Education, Distance Learning (DL), Student Centered, Active Learning

Views represented in this paper do not reflect those of the U.S. Government, the U.S. Department of Defense, or the National Defense University, but only those of the author.

\section{Introduction}

Student centered. Demonstrable outcomes. Center of gravity shifting from learned to learner. Learning by doing. Collaboration. Critical thinking. Student responsible for learning. Deeper learning. Ongoing feedback. Outcome assessment. Priority on how, not where, a student learns. Life-long learning opportunities. Global access 24/7/365. Effectiveness. Efficiency. Revolution.

These are but a few of the touted promises of distributed education (DE) that is being supported by new and evolving web based information technologies (IT). Educational periodicals bombard their readers with heralds of the IT community's pledge to revolutionize education out of the industrial age of Taylorized mass production of passive students into the knowledge age of life long active learners. Notable educations predict DE will profoundly affect the traditional classroom, forcing it to follow the DE classroom in becoming more of a student centered active learning environment. (Carnevale, April, 2001;

Material published as part of these proceedings, either on-line or in print, is copyrighted by Informing Science. Permission to make digital or paper copy of part or all of these works for personal or classroom use is granted without fee provided that the copies are not made or distributed for profit or commercial advantage AND that copies 1) bear this notice in full and 2) give the full citation on the first page. It is permissible to abstract these works so long as credit is given. To copy in all other cases or to republish or to post on a server or to redistribute to lists requires specific permission from the publisher at publister@intormingscience.org
Newman \& Scurry, 2001; Toward a model of distributed learning, 1999) Are any of these promises being actualized? The Information Resources Management (IRM) College, National Defense University, Ft. McNair, Washington, D.C. has been offering web-based interactive DE courses to its globally dispersed graduate students for over six years. The IRM College faculty, administration, 
technologists and students have moved sufficiently up the DE learning curve to have the necessary experience to delve into these very promises to determine their fact, fiction and lessons learned. The faculty has been sharing among themselves their insights in their respective DE classrooms. Some of the hype is being actualized, and there is spillover into the traditional classroom, but at a cost not always obvious to the decision makers.

\section{Background - IRM College Takes Advantage of DE to Meet Its Student's Needs}

The IRM College students are globally dispersed higher level government employees (GS-14 through SES) who work in or closely with their respective Chief Information Officer (CIO) organizations. Many cannot break away from their core responsibilities to attend the requisite length resident courses, yet they require the knowledge and critical thinking skills to perform their missions. Six years ago the IRM College recognized the potential promise of the Internet technology to help meet the needs of their students. The administration directed the faculty to test the DE concept with a limited number of courses. The students registered in increasing numbers, the faculty gained experience by developing and executing on-line courses, and appropriate technology became more available. Based on initial feedback from both students and faculty, the College administration decided to offer all of their courses in both residence and interactive DE versions. However, within a couple of years it became evident that the faculty could not keep pace with researching, procuring and learning the requisite DE technological tools while concurrently researching, designing, developing and delivering their course content. The IRM College administration resourced an in-house technology center to team with the faculty. The demand for IRM College DE courses continues to grow. By 2004 all faculty will be offering DE versions of all of their resident courses. The technology center's major tasks are to research the appropriate current and emerging technologies and instructional design tools to better support the course development and learning process and to team with the faculty in designing the deliverables. The College now has sufficient experience to glean lessons from its mature DE courses to improve the revised and new courses. What has the College learned? What are the open issues?

\section{Key Issue: Effectiveness of DE from a Learning Perspective}

The key issue that continually rises to the top by both administrators and faculty in many organizations, to include the regional accrediting bodies, is "How effective is DE for the students?"(Carnevale, 2000; Gilbert, 2001; Institute for Higher Education Policy, 2000; WASC Policy statement on distance education, 2000; Young, 2001) This question is usually asked relative to the effectiveness of the traditional classroom, rather than in absolute terms relative to the course learning objectives (Lockee, Moore, and Burton, 2002). It has generated significant strategic conversation among the faculty, administration and the technology experts across the educational community. Though this question is usually framed in relative terms, the conversation inevitably turns to student assessment, independent of method of course delivery. Student assessment implies tacit outcomes, which in turn implies measurable demonstrable goals. In educational vernacular, this translates to course objectives (i.e., at the end of the course the student will be able to....) and standards the faculty defines, communicates and uses to assess the level of student learning. (McMillan, 1997)

The IRM College team has taken advantage of this strategic conversation opportunity to step back and deliberately think about course objectives and assessment and how together they drive course content, dynamics and design. One of the critical lessons the College has learned about effective DE courses is they have to be student focused rather than instructor centered. Though obvious in theory, it is not so in practice in either the traditional or the DE classroom. (Graves, 2001; Newman et al., 2001; Toward a 
model of distributed learning, 1999) What does student focused mean? It means creating an environment where students have the opportunity to learn. But how do students learn?

Since the beginning of the teacher/student relationship, it has been recognized that students learn best by doing. (Guglielmino \& Guglielmino, 2001; Newman et al., 2001) The great teachers in both the eastern and western worlds were mentors. They guided their students by questioning and assigning them projects that lead to self-discovery, often gaining success through failure. The students took on the key responsibility of their own learning. But the printing press, the industrial revolution, standardization, and economics put this learner center approach on the back burner in many institutions. Efficient mass production of "graduates" became the goal, with seat time and credit hours becoming a key measure of effectiveness. The common approach in the non-trade and non-professional educational institutions became, and still remains, the learned lecture to the silent passive, who, in turn, vary only slightly in their regurgitation of the message on their assessment assignment, usually in form of a paper or multiple guess/short scantron answer test. This "what to think" model is what the current generation of students, faculty and administrators know best, practice and expect. It has been part of the culture in the United States since the mid 1890s when the public believed that if modern business methods were applied to schools, great efficiencies could be achieved, and the marketplace demand for productive workers could be satisfied. (Marshall \& Tucker, 1992)

The IRM College, like many other educational institutions, is discovering that DE offers the prospect and catalyst for breaking this entrenched industrial age educational culture. In many of the IRM College virtual classrooms, students and their learning are again becoming the central focus. They are encouraged to take responsibility for their own learning, are afforded the opportunity to create knowledge within themselves through doing and failing, often in collaboration with peers. (Center for Adult Learning, 2001; Feilding, 1999; Gilbert, 2001) But this has mandated faculty move from center stage to being tutors, deliberately redesigning their courses and the dynamics of the classroom to support this active learning environment that focuses on how to think and what to think about, and taking risk of sharing control with the students. The change is slow and evolutionary as cultural expectations and the dynamics of the classroom have to change.

When developing and executing their DE courses, the IRM College faculty members have universally discovered that it takes significantly longer. Why? Are not the learning objectives the same? The course content the same? The assessment process the same? The students the same? The faculty the same? Is not the only real change in the mode of delivery and the location of the students? Theoretically the answer to all of the above questions is yes. However, in reality, most of the answers are no. The new delivery method has forced faculty to think each of these areas in different ways. The remainder of this article addresses how the delivery method has impacted the thinking on learning objectives and the assessment process, thus the dynamics of the learning process itself.

What has accelerated this new thinking is that designing and executing the course are no longer the solo domains of the faculty member. Quality DE courses require a team effort, with faculty and instructional designers being the key team partners. (Armstrong, 2000; Gilbert, 2001; Lockee et al., 2002; Shank, 2002) Faculty are content experts, with few being technological specialists. Technologists and instructional designers are not necessarily content experts, but are responsible for having the capability of creating the delivery so as to maintain the integrity of the course content for a student interaction asynchronous in time or location or both. This requires ongoing dialogue among the team members, and it requires the team members to take on the role of students when checking out the course. (WestEd, 2001; Young, 2001) The student is now appropriately moving toward center stage.

The faculty member defines the learning objectives at the outset. Ideally these objectives are the drivers throughout the course design, delivery and assessment processes, but in reality they are not for traditional classroom courses. However, in the DE course design process, the learning objectives keep coming to the 
forefront for clarity. (WestEd, 2001) The instructional designers need to have a clear understanding of the faculty member's intent in order to explore the best way to leverage the technology for each lesson. As a result, the faculty member has to hone each course and lesson objective for clarity and measurability continuously throughout course development. This mandates conversation among the faculty and technology team members, and this conversation has had high payoffs for the students. The function of the learning objectives is moving toward the ideal - the center of gravity of the course for the student, the faculty and the instructional designer.

When designing the DE course, the issue of student assessment repeatedly arises up front rather than after the course has been put together, as is too often the case in the traditional classroom courses. First of all, the entire DE course is usually developed as a whole package before the first lesson is launched as near real time changes during the course often require unavailable time for design and technical execution. Assessment has to be built in throughout the course. (Lockee, et al., 2002) Second, the usual reliable cues upon which faculty rely, such as body language, tone, inflection, raised hands, spontaneous questions, and overall climate are no longer available thermometers of student progress. (Doug, 2001) Most of the College professors want a measure or at least have a sense of each student's progress before the end of the course. Third, students want and need to know at the outset how they are going to be evaluated, and they want feedback during the course, as they too no longer have the nonverbal cues to gauge their progress or collocated peers who have previously taken the course to give them insights. This need is especially strong among DE students who may tend to feel isolated. (Institute for Distance \& Distributed Learning, 2001, Decreasing the distance; Institute for Distance \& Distributed Learning, 2001, Managing student expectations; Gilbert, 2001; Rosenberg, 2001; WASC, 2000, Curriculum and instruction)

In this area of assessment, DE can make a major contribution to the promise of changing the industrial age passive educational culture. DE invites active student learning which is demonstrable and, if done properly, measurable. Roger Schank captures this point, "computers are inherently doing devices rather than listening devices, so courses can be based upon doing." (Brockman, 1999, p. 4) DE lessons can be designed so the students are actively immersed, doing, networking, and producing rather than engaging in the "tedium of listening to the lecture," or "tedium of reading from the screen." (Bostock, 1997, p. 225) They are now taking responsibility of their learning and determining the depth and breadth. (Graves, 2001) But this just does not happen. It takes deliberate team effort from the faculty, technologists, instructional designers, and resources from the administration. The faculty and instructional design team members review the learning objectives, this time clarifying them to insure they are demonstrable and measurable not only at the end of the course, but throughout as milestones for faculty and students. (Graves, 2001) They research resources, create possible activities and determine the best match for the learning objectives, the students and the available technology. (Shank, 2002) The options have outgrown the confines of the standard textbook, paper, test or a snapshot at discrete periods. Students, working solo or in virtual teams, can engage in projects and/or in critical analysis of a reading or concept. They can post their papers or presentations for sharing content, critical analysis and/or rework. They can each build a personal portfolio over the duration of the course or program, with a critical self and faculty review and assessment at the conclusion. Because of the nature of the virtual classroom, all of the communication and projects are documented. This documentation captures not only what has been learned, but also the process of each student's learning. It gives faculty insight into every student's contributions throughout the entire course, as in the virtual classroom students can no longer hide by virtue of the crowded classroom, the extroverts who dominate, or the discipline of the clock. Faculty has access to cumulative information upon which to reflect and tailor further insights, directions or corrections when and where a student may need it. This ongoing documented assessment method is moving the faculty member toward the tutor model. DE allows for continual assessment of the learning and the learned. This process of developing a DE course has been a catalyst in integrating learning objectives, assessment, and student activities. (Newman et al., 2001) It forces the learning objectives to be explicit and defined so they are de- 
monstrable by student activities. This in turn defines the assessment, which drives the student activities. All students need to produce to be successful, and not jut at the end of the course. The learning process is critical at all levels for both student and faculty.

\section{Cost Is Higher but the Cost/Benefit Is under Investigation}

DE has the potential to deliver on some of the promises, with the key one of moving the students and their learning back to center stage. There are costs however, which many administrators are relooking in relationship to the benefits and their mission. (Lockee et al., 2002; Welsch, 2002) Like the tutoring model of learning, which was largely overtaken by the mass production model because of efficiencies of the latter, DE is more labor and resource intensive. (Doug, 2001; Institute for Distance \& Distributed Learning, 2001, Timelines and planning for online courses; Jones, 2001; Young, 2000)

All IRM College faculty who teach their courses in both the traditional and the interactive DE classrooms agree that DE courses take significantly longer (at least four to five times longer) to research, design, develop and deliver. Interactive DE classrooms are labor intensive and require additional technology tools, some which require upgrading and relearning on a regular basis. When designing the course, the faculty member needs to team with the instructional designers who keep up with the latest technologies in what they have to offer and how to leverage them. This requisite teaming hinders the faculty member in efficiencies and course content currency. The faculty is slave to the instructional team's office hours, tempo and schedule. Faculty members often create their lessons out of the office and not always during the instructional designers' working hours. When an idea comes, the faculty member no longer has control of the execution, but must document it for later discussion with the instructional designers at the latter's convenience. When the ratio of faculty to instruction designer is medium to high, faculty members find themselves competing with other faculty and the administration's projects for the instructional designer's time. Also, most faculty are not satisfied with having to have the entire course ready to give to the designers three to six months prior to actually launching the course. In the CIO competency areas the IRM College teaches, students need and demand the latest information, which a three to six month production schedule is not well suited to support. (Lockee et al., 2002)

There is a natural tension between the faculty and instructional technologists. The latter are incessantly nagging to experiment with new capabilities. They know the virtual students expect high quality graphics and streaming video that make the content interesting. These productions are labor and resource intensive to produce to sufficient quality, and sometimes run the risk of not being able to be appropriately supported by the all students' computer systems. Then, when the production is complete, there is a hesitancy to change its content on a regular but needed basis because of the effort and time required both in the initial and change production.

After the student has enrolled in a course, the faculty member represents the institution throughout the course delivery. When the system fails in any way from the student perspective, the student turns to the faculty member, who again, is slave to the instructional team's availability. Data shows that IRM College students do a majority of their work between Friday early evening through late Sunday evening, with most of the remainder during the workweek late evenings. The instruction design team member's office hours do not yet match that of the faculty and students. Problems with the technology and the time delay to resolve them continue to be high dissatisfiers for both students and faculty.

Class size of the IRM interactive DE courses is the same as those of the traditional classroom, yet the faculty member is mentoring, on a regular basis, each individual student. The DE classroom is open to students 24/7, and they take advantage of it. This is one of the premium promises. When the course is designed for active interaction among the students, the faculty member keeps the direction of the course focused and assessment of each student by routinely reading all of the traffic among the students. This means the faculty is on line at minimum on a daily basis, and usually four or more times throughout the 
day, especially during periods of high student interaction. This is necessary, but time intensive. Providing feedback to students is a critical part of their learning process and assessment. The feedback needs to content laden, responsive, and tailored to a DE student. (Doug, 2001; Graves, 2001; Newman et al., 2001) This written feedback takes longer than the verbal that is usually provided in the traditional classroom, not only because it is usually more reflective on a wider range of activities, but it is written, written to be read in lag time, and written for a student the faculty member may not know.

IRM College faculty members also agree, based on both the interaction during the class and the end of course projects, that the DE students produced higher quality projects than those taking the same course in the traditional classroom. In the DE classroom, the students drive the depth and breadth of the course, often beyond the learning objectives. This adds to the richness of the DE interchange, but also the intensity of involvement by both student and faculty. The IRM College administration recognizes there are different costs with the DE model. With the faculty and the instructional designers, they are working to better understand and define the differences in order to try to figure the cost benefit in terms of the IRM College mission.

\section{Conclusion - DE Can Deliver and to More than the DE Students}

All of the IRM College faculty who teach DE courses also teach the same course in the traditional classroom. Many have taken the opportunity to reflect on what makes their DE classroom so rich and have been experimenting with some of the same methods in their traditional classroom. Active student learning with demonstrable assessment are two areas of their focus. With the administration's support, the college is experimenting with a mixed model, applying the appropriate methods from each to best support the learning process. The process is iterative but evolving in a very positive direction. So can DE deliver on the hype? The initial insights that the IRM College has gleaned from their six years of experience indicate it can in most of the promised areas, but with costs that need to be recognized and resourced. But more importantly may be the effect DE can have on the traditional classroom. Students and faculty of active student centered DE courses may no longer be satisfied with the industrial passive what to think content is king model of the classroom.

\section{References}

Armstrong, Llyod. (2000, November/December). Distance learning. Change, 32(6), 8.

Bostock, Stephen J. (1997). Designing Web-based instruction for active learning. Web Based Instruction, Khan, B. H. (Editor). NJ: Educational Technology Publications, 225-230.

Brockman, John (1999, August 16). The disrespected student-or-the need for the virtual university: A talk with Roger Schank. Edge (59), 1-16. Retrieved October 1, 2001 from the World Wide Wed: http://WwW.edge.org/documents/archive/edges9.htm

Carnevale, D. (2000, July 7). Faculty union opposed undergraduate degrees earned entirely through distance education. The Chronicle of Higher Education, 46(46) A32.

Carnevale, D. (2001, February 2). Union offers standards for distance education. The Chronicle of Higher Education, 47(21), A21.

Carnevale, D. (2001, April 13). Assessment takes center stage in online learning. The Chronicle of Higher Education, 47(31), A43-A45.

Carnevale, D. (2001, June 29). A researcher says that professors should be attentive to students' approaches to learning. The Chronicle of Higher Education Daily News. Retrieved June 29, 2001 from the World Wide Web: hittp:/tchronicle.com/distancet

Center for Adult Learning. (2001, January 31) Distance learning: Information and resources. American Council on Education ACEnet. Retrieved February 13, 2001 from the World Wide Web: http://www.acenet.edu/calec/dis_learning/di_coreValues.htm! 
Doug, F. H. (2001, September). Can you succeed as a cyberstudent? How to develop communications skills on the web. $e$ Learning, 12-16. Retrieved October 1, 2001 from the World Wide Web: http://www.elearningmag.com/issues/Sept0//cyberstudent.aspsp

Feilding, Randall (1999, May). Death of a classroom, learning cycles and Roger Shank. Retrieved February 13, 2001 from the World Wide Web: hittp://www.designshare.com/Research/shank1.htm

Gilbert, Sara D. (2001). How to be a successful online student. NY: McGraw-Hill.

Graves, William H. (2001, February 5). Framework for an enterprise e-learning strategy. (Article to be published in upcoming Educause)

Guglielmino, Paul J.; Guglielmino, Lucy M. (2001, Summer). Moving toward a distributed learning model based on selfmanaged learning. SAM Advanced Management Journal, 66(3), 36-43.

Institute for Distance \& Distributed Learning. (2001). Decreasing the distance. Virginia Technical University Educational Handbook. Retrieved September 27, 2001 from the World Wide Web: http://www.iddt.vt.edu/handbook/decrease.php

Institute for Distance \& Distributed Learning. (2001). Details to include on the course website. Virginia Technical University Educational Handbook. Retrieved September 27, 2001 from the World Wide Web: http://www.iddl.vt.edu/handbook/syllabus.php

Institute for Distance \& Distributed Learning. (2001). Managing student expectations. Virginia Technical University Educational Handbook. Retrieved September 27, 2001 from the World Wide Web: hlup.//www.iddt.vt.edu/handbooktexpectation.php

Institute for Distance \& Distributed Learning. (2001). Timelines and planning for online courses. Virginia Technical University Educational Handbook. Retrieved September 27, 2001 from the World Wide Web: http://www.iddl.vt.edu/handbook/webplan.php

Institute for Higher Education Policy. (2000, April). Quality on the line: Benchmarks for success in Internet-based distance education. Retrieved February 22, 2001 from the World Wide Web: http://www.ihep.com/quality.pdf

Jones, Chris (2001, January). Ain't got time to teach. Online Learning, 62-68.

Lockee, Barbara, Moore, Mike, \& Burton, John (2002). Measuring success: Evaluation strategies for distance education. Educause Quarterly, 1, 21 - 26.

Marshall, Ray \& Tucker, Marc. (1992). Thinking for a living. NY: Basic Books.

McMillan, James H. (1997). Classroom assessment: Principles and practice for effective instruction. Boston: Allyn and Bacon

Newman, Frank \& Scurry, Jamie. (2001, July 13). Online technology pushes pedagogy to the forefront. The Chronicle of Higher Education, B7-B10.

Rosenberg, Marc J. (2001). e-Learning. NY: McGraw Hill.

Shank, Patti (2002, February). New skills for a new field. Online learning, 6(2), 34-36.

Toward a model of distributed learning: An interview with Mike Fitzgerald. (1999, Nov/Dec ). Educom Review, 34(6), 40-42.

WASC (Western Association for Schools and Colleges). (2000). Principles of good practice. Retrieved January 31, 2001 from the World Wide Web: http://www.wascweb.org/senior/guide/pgpa.html

WASC. (2000). WASC policy statement on distance education. Retrieved January 31, 2001 from the World Wide Web: http://www.wascweb.org/senior/guide/policy.htm

Welsch, Ed. (2002, January). Cautious steps ahead. Online learning, 6(1), 20-24.

WestEd. (2001). Designing instruction for web-based distance learning. Practitioner's Guide to Designing Instruction for Web-Based Distance Learning. Retrieved March 1, 2001 from the World Wide Web: http://www.dlrn.org/educ/course.htm

Young, J. R. (2000, March 3). Dispatches from distance education, where class is always in session. Chronicle of Higher Education, 40(26), A41.

Young, J. R. (2001, February 2). Time-management skills are one key to success for online students. Chronicle of Higher Education, 47(21), A20. 